\title{
Three Dimensional OCT in the Engineering of Tissue Constructs: A Poten- tially Powerful Tool for Assessing Optimal Scaffold Structure
}

\author{
K. Zheng ${ }^{1}$, M.A. Rupnick ${ }^{2,3}$, B. Liu ${ }^{1,3}$ and M.E. Brezinski ${ }^{1,3, *}$ \\ ${ }^{I}$ Department of Orthopedic Surgery, Brigham \& Women's Hospital, Boston, MA; ${ }^{2}$ Cardiology Division, Brigham and \\ Women's Hospital, Boston, MA and ${ }^{3}$ Harvard Medical School, Harvard University, Boston, MA, USA
}

\begin{abstract}
Optical Coherence Tomography (OCT) provides detailed, real-time information on the structure and composition of constructs used in tissue engineering. The focus of this work is the OCT three-dimensional assessment of scaffolding architecture and distribution of cells on it. PLGA scaffolds were imaged in two and three-dimensions, both seeded and unseeded with cells. Then two types of scaffolds were reconstructed in three dimensions. Both scaffolding types were examined at three different seeding densities. The importance of three-dimensional assessments was evident, particularly with respect to porosity and identification of asymmetrical cell distribution.
\end{abstract}

\section{INTRODUCTION}

The micro engineering of tissue is an exciting potential approach to treat many disorders, from osteoarthritis to coronary artery disease. Tissue engineering (TE) uses a multidisciplinary approach to generate viable tissues from non-differentiated cells by designing matrix/polymer scaffolds, controlling growth factors, and bioreactor cultivation systems to support the in vitro formation of a tissue construct that mimics native tissues in structure and function $[1,2]$. The ultimate objective is to produce tissues to repair, replace, preserve or augment organ function that has been lost to injury, disease, congenital defects or aging. Promising advances in a number of engineered tissues (bladder, skin, muscle, bone, cartilage, tendon, breast, aorta) support the feasibility of translating TE to improve the quality of human life [3-10]. However, full realization of this goal is impeded by the need for new real time monitoring techniques that nondestructively assess scaffolding architecture, as well as monitoring the interaction of cells and their environment during the engineering process. Currently, histological techniques are used to characterize the constructs and make structure and composition comparisons to their naturally occurring counterparts. These approaches still require that the samples be processed before examination, which alters the construct, and can distort the architecture. Furthermore, the constructs are consumed in these techniques. This limits the data obtained from each sample, significantly increasing the number of constructs required to establish findings. More sophisticated technologies are required to analyze the constructs, allowing them to be nondestructively evaluated initially and over time.

Optical Coherence Tomography (OCT) is able to provided detailed, real-time information on the structure and composition of tissue in three dimensions to depths of about $3 \mathrm{~mm}$ with resolutions between 4-20 um [11-13]. Character-

*Address correspondence to this author at the Harvard Medical School, Harvard University, Boston, MA, USA; E-mail: mebrezin@mit.edu istics of the construct that can potentially be followed by OCT include scaffold architecture, tissue organization, tissue type, total matrix generation, and tensile properties of the tissue. These tissue properties can be followed in the setting of changing culture environment to optimize conditions.

The correct development of bioengineered tissue requires the control of a wide range of environmental factors $[1,2,14]$. One application of OCT is as a non-destructive method able to provide detailed information on the spatial and temporal changes of different tissue elements in three dimensions in response to varying environmental conditions. This would allow investigators to screen, identify and optimize these parameters to facilitate the formation of usable tissue. Ultimately, OCT could be developed to monitor the incorporation of engineered tissue in vivo determining biocompatibility and function.

The focus of this work is in assessing another area, scaffolding architecture. Scaffold design is becoming increasingly important for tissue engineering applications as properties such as scaffold surface characteristics (ie: adhesions molecules), porosity, pore size, degree of interconnectivity, rate of degradation, and tensile strength affect cell penetration and subsequent tissue infiltration and development [1518]. For example, a common problem encountered when using certain scaffolds with limited porosity for tissue engineering is the rapid formation of tissue on the outer edge, which leads to the development of a necrotic core due to limitations of cell penetration and nutrient exchange [17,19].

In this preliminary work we demonstrate the importance of three-dimensional high speed OCT reconstruction of scaffold structure and subsequent cell adhesion. Several objectives were examined. First, PLGA scaffolds were imaged in two and three dimensions, both seeded and unseeded with a tumor cell line, to demonstrate the importance of three dimensional reconstruction. Second, two types of scaffolds were imaged (again both seeded and unseeded) in three dimensions to emphasize relative differences. Finally, both scaffolding types were examined after three different seeding 
densities showing how suboptimal design leads to heterogeneous growth in the scaffold. The importance of three over two dimensional assessments was evident, particularly with respect to porosity establishing and identifying asymmetrical growth. Work is currently underway to quantify scaffolding porosity, both with and without seeding, through image processing techniques.

\section{MATERIALS AND METHODOLOGY}

Images of Type I bovine Achilles collagen sponges (Helistat $^{\circledR}$, Integra LifeSciences Corporation, Plainsboro) and Poly(lactide-co-glycolide) (PLGA) scaffolding (Boehringer Ingelheim, Ingelheim, Germany) were obtained. Seeding was performed with human embryonic kidney cells (HEK 293, ATCC, Manassas, VA).

HEK cells were cultured in DMEM 11995, 10\% fetal calf serum, $1 \%$ non-essential amino acids (Invitrogen, Carlsbad, $\mathrm{CA}), 100 \mathrm{U} / \mathrm{ml}$ penicillin $+100 \mathrm{ug} / \mathrm{ml}$ streptomycin $\left(37^{\circ} \mathrm{C}\right.$, $5 \% \mathrm{CO}_{2}$ ). Scaffolds were placed singly into wells of 12 -well tissue culture plates. HEK cells were rinsed and detached using $0.25 \%(\mathrm{w} / \mathrm{v})$ Trypsin- $0.53 \mathrm{mM}$ EDTA, then washed and re-suspended in culture media. Cells were plated onto dry scaffolds at a high ( $4 \times 10^{6}$ cells/scaffold) or low density ( $2 \times 10^{6}$ cells/scaffold) in a final volume of $1 \mathrm{ml}$ each and allowed 2 hours to attach $\left(37^{\circ} \mathrm{C}, 5 \% \mathrm{CO}_{2}\right)$. An additional 2 $\mathrm{ml}$ of media were then added to each well to prevent drying. The seeded scaffolds were incubated for $24 \mathrm{hrs}$ before imaging.

A LightLab OCT imaging engine was used with a wideband light source. It has an axial resolution of $12 \mu \mathrm{m}$ and captures images at a rate of 10 frames per second (pixels 800 x 304, radial x azimuthal). The lateral resolution was $25 \mu \mathrm{m}$.
The power on the sample was $15 \mathrm{~mW}$. The schematic for the system is shown in Fig. (1).

An OCT Imagingwire $(\subset$ was used as the probe. The wire had a cross sectional diameter of 0.019 " and was placed $1.2 \mathrm{~mm}$ away from the surface of each sample at the focal length. The pullback rate was $0.5 \mathrm{~mm} / \mathrm{sec}$ and video streams were taken of each sample. Video streams of the sample were saved in JPEG frame stream (with the option of AVI). Each JPEG provided a two dimensional image. Threedimensional reconstructions of the samples were made during post processing using Image J. The saved JPEG stream was converted to gray scale. The parameters set were a projection method of the brightest point, axis of rotation in the $\mathrm{Y}$ direction, and rotation angle increment of 3 degrees. The reconstructions were saved as MPEG movies.

\section{RESULTS}

The two scaffold types used in this study were PLGA and Helistat ${ }^{\circledR}$. As seen in Fig. (2), photographs of the two types of scaffold show that the porosity of each is clearly visible to the naked eye, but the composition distinct.

The degree to which the imaging modality is able to assess this porosity is compared using both two-dimensional and three-dimensional imaging. In Fig. (3a), a PLGA scaffold was imaged with OCT in two-dimensions unseeded, while in Fig. (3b), the PLGA scaffold was seeded with 2 million HEK cells. It can be seen that in two-dimensions, little detail is noted in the image and it is difficult, if not impossible, to assess both porosity and the degree of cell growth.

Next, the PLGA scaffold was imaged in three-dimensions. One rotational frame of a three-dimensional graft re-

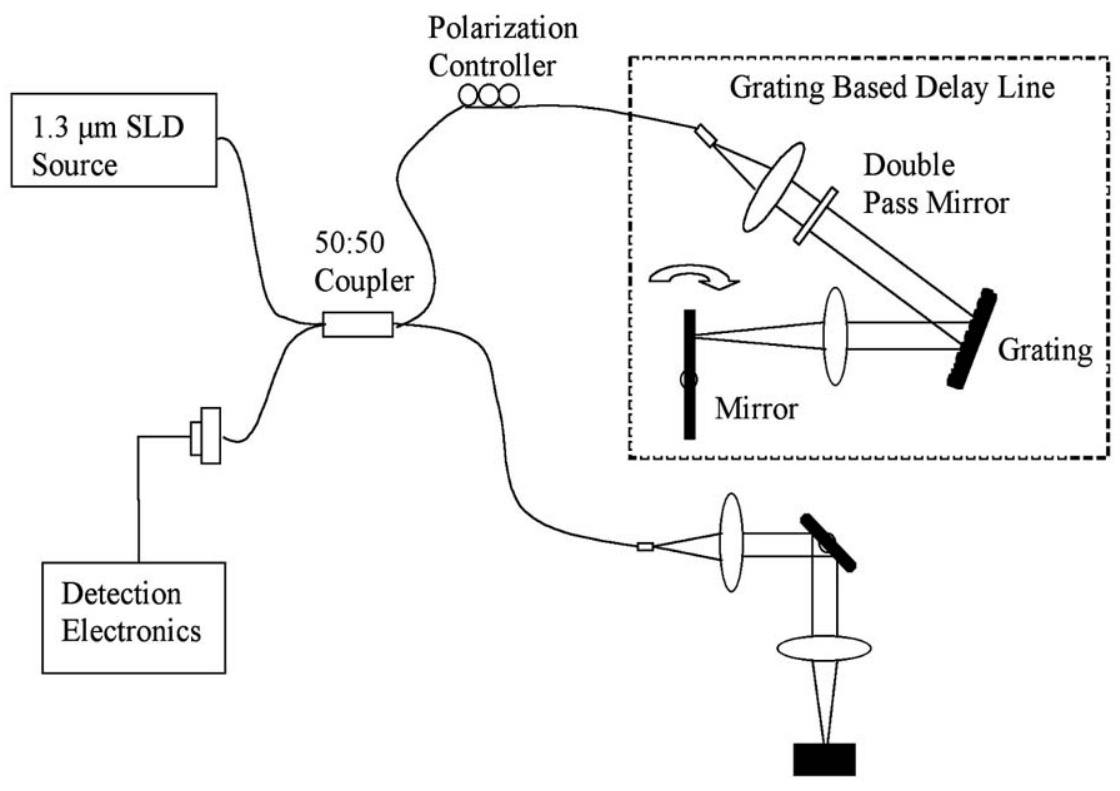

Fig. (1). This image demonstrates a schematic of the OCT system used to generate images of the seeded and unseeded scaffolding. Imaging was performed at 10 frames per second that allowed rapid three-dimensional high-resolution reconstruction. The light source operates at a central frequency of 1300 nanometers that corresponds to an axial resolution of 10 microns measured from the point spread function off a mirror. The lateral resolution is approximately 25 microns. The scan rate is up to 3000 lines per second with a dynamic range of 100 decibels. The power on the sample was 10 milliwatts. An imaging catheter was used that was 0.019 inches in diameter with a focal line length of 2.0 millimeters. Recorded data was reconstructed in 3-D with Image J. 

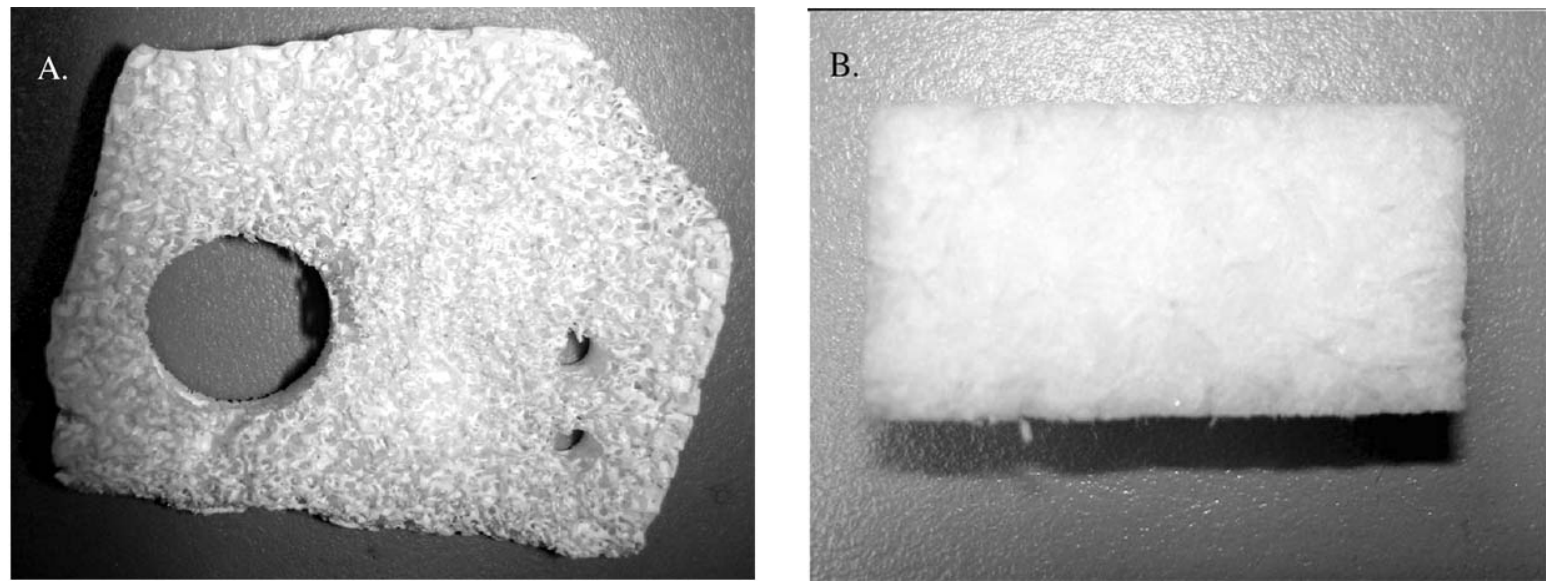

Fig. (2). Photographs of unseeded PLGA (a) and Helistat scaffolding (b). The porosity can be noted.
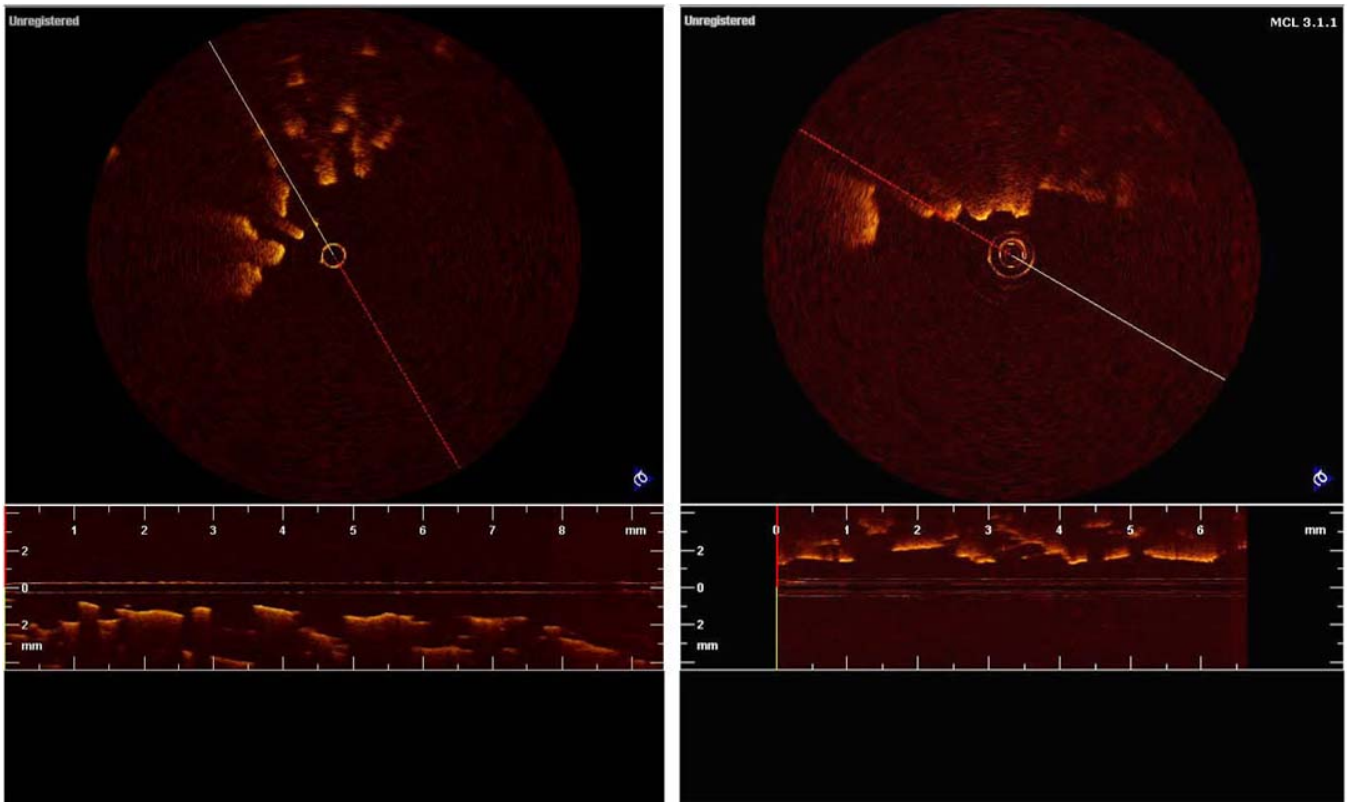

Fig. (3). Figs. (3a) and (3b) show two dimensional images of PLGA scaffolding unseeded and seeded, respectively. The scaffolds were seeded with human embryonic kidney cells (HEK-293). It can be seen that in two dimensions little detail is noted in the image and it is difficult, if not impossible, to assess both porosity and the degree of cell growth.

construction is shown in Fig. (4a). Low density cell seeding (1 million), as shown in Fig. (4b), and with high density cell seeding ( 2 million), as shown in Fig. (4c) emphasize the asymmetrical distribution. In all three three-dimensional images, it can be seen that the pore size and distribution is well delineated compared to the two-dimensional images in Fig. (3). In Fig. (4b) we see cell growth in the scaffolding and the loss of porosity (arrow). In the periphery of the scaffolding there has been an almost complete loss in pores while the area most distant to the center still shows strong evidence of porosity, emphasizing asymmetrical distribution.

Helistat $^{\circledR}$ scaffolding was also imaged in three-dimensions, with one sample imaged unseeded (5a), a second sample with low density cell seeding (5b), and a final sample with high density cell seeding (5c). Helistat ${ }^{\circledR}$ scaffolding consists of collagen Type I and as seen, consists of a much looser pattern. It can be seen in Fig. (5b) that the largest concentrations of cells occur on the outside of the Helistat ${ }^{\circledR}$ sponge with relatively little present in the interior. In Fig. (5c), the density has increased, but the center of the graft again still remains relatively unseeded.

\section{DISCUSSION}

Various scaffoldings available for tissue engineering include synthetic polymers, collagen based sponges, and silk, with this study looking at the first two. Synthetic polymers include PLA (polylactic acid), PGA (polyglycolic acid), and PLGA (Poly lactic- co glycolic acid). Advantages include plentiful supply, precise control of composition, and management of biocompatibility [19]. The greatest disadvantage is that they do not contain an active biological surface such as adhesion molecules, similar to a basement membrane. Collagen based scaffolds are easily attainable [20]. However, they are fast degrading, resulting in poorer total cell load and tissue formation. Silk, while biodegradable, has a relatively slow breakdown rate as well as a high porosity, and excellent structural integrity [21]. However, it is difficult to synthesize and therefore it is not currently widely available. Ultimately 

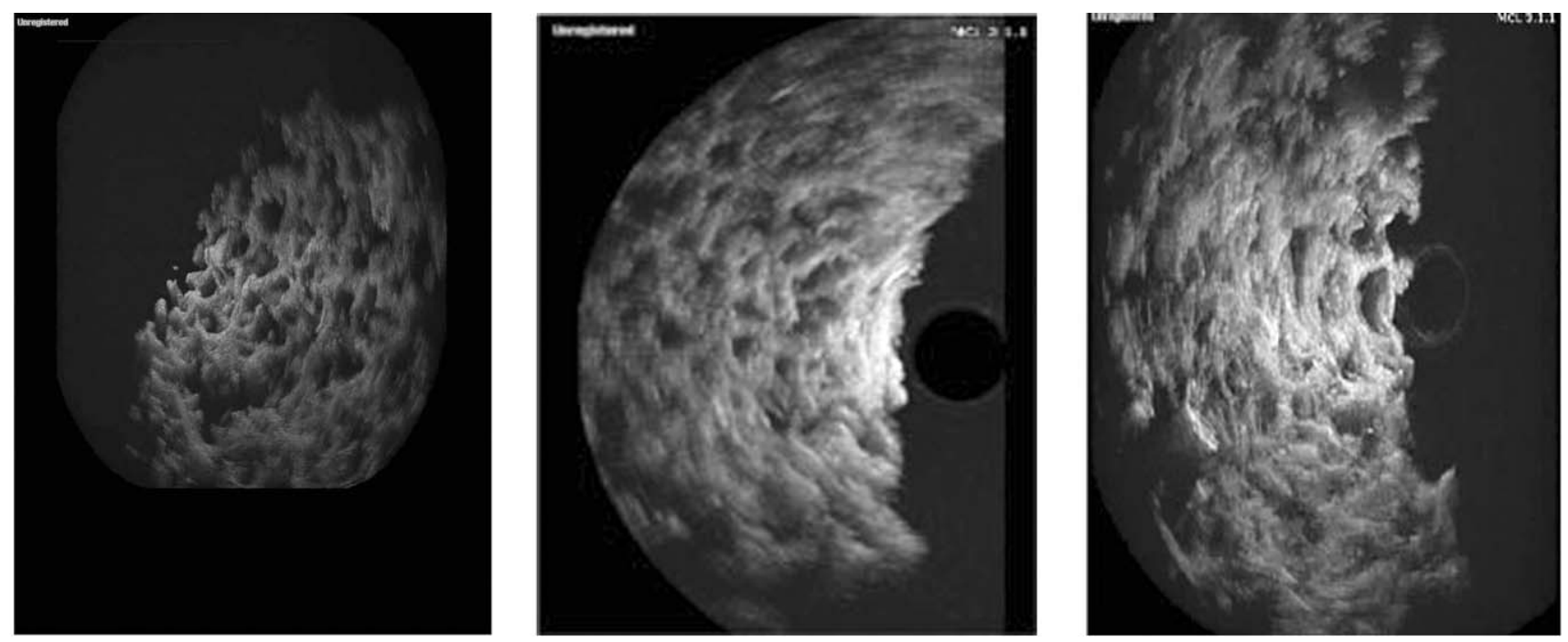

Fig. (4). This figure shows unseeded (a), low density cell seeding (b), and high density cell seeding in PGLA scaffolding imaged in three dimensions. In 4a one rotational frame of the three dimensional scaffolding image is shown. We can see that pore size and distribution is well delineated compared to Fig. (3). In Fig. (3b) we see cell distribution in the scaffolding and the loss of porosity (arrow). This sample was seeded with 1,000,000 HEK-293 cells. In Fig. (3c) the scaffolding has been seeded with 2 million cells. In the periphery of the scaffolding there has been an almost complete loss in pores while the area most distant to the center still shows strong evidence of porosity, emphasizing asymmetrical distribution.
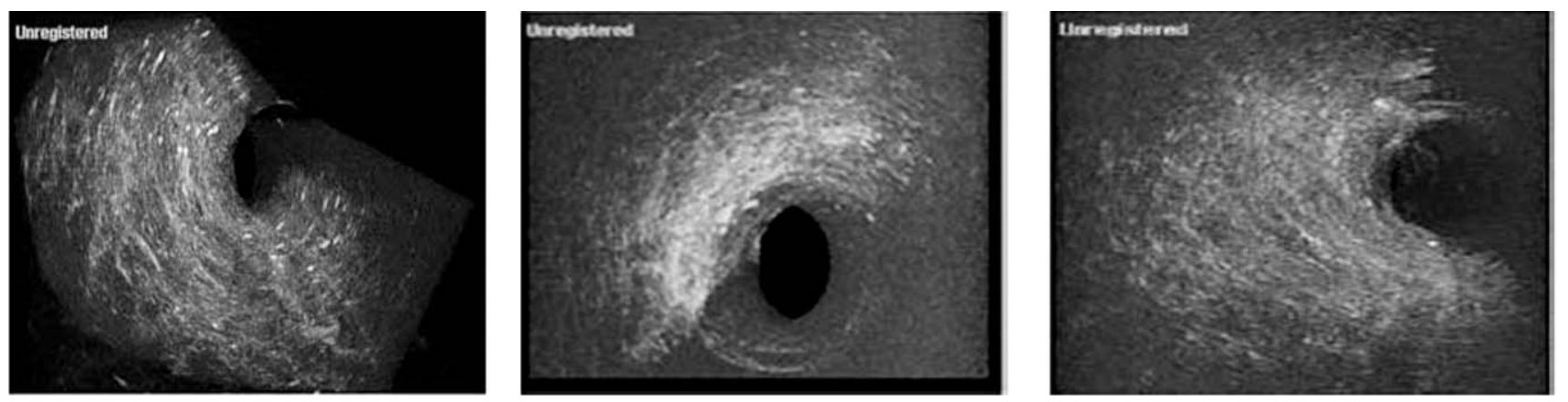

Fig. (5). Three-dimensional imaging of the Helistat ${ }^{\circledR}$ scaffolding. In 5a a Helistat ${ }^{\circledR}$ scaffolding that consists of collagen type one, is shown in an unseeded sample. In image b, the scaffolding sample has been seeded with 1,000,000 cells (slightly higher due to the looseness of the collagen) and a reduction in the porosity is noted. However, it can be seen that the largest concentrations of cells occur on the outside of the Helistat ${ }^{\circledR}$ sponge with relatively little present in the interior. In image 5c, it is noted that where 2,000,000 cells are used to seed the graft the density has increased, however, the center of the graft again still remains relatively unseeded.

though, whatever scaffolding is used, optimal structural design is unknown in large part due to limited availability of real time, high resolution imaging to assess differences among scaffolds. It should also be noted that, while not examined in this paper, high resolution real time imaging also has the potential to assess the rate of scaffold breakdown.

Various imaging modalities have been used to examine tissue engineered cartilage to avoid destructive histology. These include confocal microscopy, MRI, and micro-CT
[22-26]. While confocal microscopy can generate resolutions below $50 \mathrm{um}$, its penetration is limited to less than $200 \mathrm{um}$, greatly reducing its usefulness. It is not anticipated that two photon fluorescence will dramatically improve significantly upon these results [11]. Furthermore, expensive, complex femtosecond sources are required for imaging. Magnetic resonance imaging (MRI) is a powerful technique for a wide range of clinical scenarios. It has been used both to assess tissue distribution and flow velocities within samples. How- 
ever, the combination of its cost, acquisition time, and the need for contrast dyes makes it impractical for routinely following the development of bioengineered tissue. Micro-CT has the ability to detect micro-calcification or other radiodense structures. However, it is expensive, not real time, and many non-calcified tissues are poorly visualized.

OCT represents a promising tool for both reconstructing scaffolding and following tissue development as a function of time, but little work has been done in this area. While construct studies have looked at two dimensional OCT imaging, Doppler flow rates, and oxygenation, essentially no work has been performed on the three dimensional reconstruction of scaffolds, particularly for the assessment of porosity [27-31]. In this study, the feasibility of three dimensional OCT was demonstrated both for assessing scaffold architecture as well as cell distribution. Future work in this area will focus on developing quantitative methods for assessing porosity, average pore size, and the standard deviation of pore size through imaging processing techniques [3236].

A small guide wire was used in this study that would allow imaging within the bioreactor without the sample removal. However, without the possible exception of measuring local flow rates or oxygenation, imaging can be preformed outside the bioreactor more accurately outside the sample as long as sterile conditions are maintained.

\section{CONCLUSION}

Three dimensional OCT represents an attractive new technology for guiding tissue engineering. Among its most attractive features is its ability to define scaffolding structure, including porosity, and identify tissue distribution on the scaffolding. Future work is required to quantify scaffold parameters as well as establish which scaffold characteristics are most likely to lead to the successful growth of the bioengineered tissue.

\section{ACKNOWLEDGEMENT}

Dr. Brezinski's work is currently funded by National Institute of Health Grants R01 AR44812, R01 HL55686, R01 EB02638/HL63953, R01 AR46996 and R01 EB000419. Dr. Rupnick's work is funded by NIH K02HL71840 and AHA \#0455824.

\section{REFERENCES}

[1] Lanza R, Langer R, Vacanti JP. Principles of Tissue Engineering, $2^{\text {nd }}$ ed. Burlington: Massachusetts, 2000

[2] Freed LE, Novakovic-Vunjak G. Tissue Engineering Bioreactors. In: Lanza RP, Langer R, Vacanti J, Eds. Principles of tissue engineering, $2^{\text {nd }}$ ed, Academic, San Diego; 2000; Chap 23: pp. 143-156.

[3] Frimberger D, Lin HK, Kropp BP. The use of tissue engineering and stem cells in bladder regeneration. Regen Med 2006; 1(4): 42535 Review.

[4] Clark RA, Ghosh K, Tonnesen MG. Tissue engineering for cutaneous wounds. J Invest Dermatol 2007; 127(5): 1018-29 Review.

[5] Carrier RL, Rupnick MA, Langer R, Schoen FJ, Freed LE, VunjakNovakovic G. Effects of oxygen on engineered cardiac muscle. Biotechnol Bioeng 2002; 78(6): 616-624.

[6] Ye H, Xia Z, Ferguson DJ, Triffitt JT, Cui Z. Studies on the use of hollow fibre membrane bioreactors for tissue generation by using rat bone marrow fibroblastic cells and a composite scaffold. J Mater Sci Mater Med 2007; 18(4): 641-8.
[7] Raghunath J, Salacinski HJ, Sales KM, Butler PE, Seifalian AM. Advancing cartilage tissue engineering: the application of stem cell technology. Curr Opin Biotechnol 2005; 16: 503-509.

[8] Doroski DM, Brink KS, Temenoff JS. Techniques for biological characterization of tissue-engineered tendon and ligament. Biomaterials 2007; 2: 187-202.

[9] Patrick CW. Breast tissue engineering. Annu Rev Biomed Eng 2004; 6: 109-30 Review.

[10] Kim SS, Lim SH, Hong YS, et al. Tissue engineering of heart valves in vivo using bone marrow-derived cells. Artif Organs 2006; 30(7):554-7.

[11] Brezinski ME. Optical Coherence Tomography, Principle and Practice. Burlington: MA, 2006.

[12] Huang D, Swanson EA, Lin CP, et al. Optical coherence tomography. Science 1991; 254: 1178-1181.

[13] Brezinski ME, Tearney GJ, Bouma BE, et al. Optical coherence tomography for optical biopsy: Properties and Demonstration of Vascular Pathology. Circulation 1996; 93: 1206-1213.

[14] Carrier RL, Rupnick MA, Langer R, Schoen FJ, Freed LE, VunjakNovakovic G. Perfusion improves tissue architecture of engineered cardiac muscle. Tissue Eng 2002; 8: 175-188.

[15] Meinel L, Karageorgiou V, Fajardo R, et al. Bone tissue engineering using human mesenchymal stem cells: effects of scaffold material and medium flow. Ann Biomed Eng 2004; 32: 112-122.

[16] Karageorgiou V, Kaplan D. Porosity of 3D biomaterial scaffolds and osteogenesis. Biomaterials 2005; 26: 5474-549I.

[17] Silva M, Cyster LA, Barry JJ, et al. The effect of anisotropic architecture on cell and tissue infiltration into tissue engineering scaffolds. Biomaterials 2006; 27: 5909-5917.

[18] Huang CT, Mauck RL, Wang CC, Lima EG, Ateshian GA. A paradigm for functional tissue engineering of articular cartilage via physiologic deformational loading. Ann Biomed Eng 2004; 32: 3549 .

[19] Vert M, Mauduit J, Li S. Biodegradation of PLA/GA polymers: increasing complexity. Biomaterials 1994; 15: 1209-1213.

[20] Dreger SA, Thomas P, Sachlos E, et al. Potential for synthesis and degradation of extracellular matrix proteins by valve interstitial cells seeded onto collagen scaffolds. Tissue Engin 2006; 12(9): 2533-40.

[21] Sofia S, McCarthy MB, Gronowicz G, Kaplan DL. Functionalized silk based biomaterials for bone formation. J Biomed Mater Res 2001; 54: 139-149.

[22] Litzlbauer HD, Neuhaeuser C, Moell A, et al. Three dimensional imaging and morphometric analysis alveolar tissue from microfocal $\mathrm{x}$ ray computed tomography. Am J Physiol Lung Cell Mol Physiol 2006; 291: 535-545.

[23] Smith IO, Ren F, Baumann MJ, Case ED. Confocal laser scanning microscopy as a tool for imaging cancellous bone. J Biomed Res Part B, Appl Biomater 2006; 79: 185-192.

[24] Chen CT, Fishbein KW, Torzilli PA, Hilger A, Spencer RG, Horton WE. Matrix fixed density as determined by magnetic resonance microscopy of bioreactor derived hyaline cartilage correlates with biochemical and biomechanical properties. Arthritis Rheum 2003; 48: 1047-1056.

[25] Potter K, Sweet DE, Anderson P, et al. Non-destructive studies of tissue engineered phalanges by magnetic resonance microscopy and $\mathrm{x}$-ray microtomography. Bone 2006; 38: 350-358.

[26] Mulder L, Koolstra JH, Van Eijden TM. Accuracy of micro CT in the quantitative determination of the degree and distribution of mineralization in developing bone. Acta Radiol 2004; 45: 769-777.

[27] Yang Y, Dubois A, Qin XP, Li J, El Haj A, Wang RK. Investigation of optical coherence tomography as an imaging modality in tissue engineering. Phys Med Biol 2006; 51(7): 1649-59.

[28] Ko HJ, Tan W, Stack R, Boppart SA. Optical coherence elastography of engineered and developing tissue. Tissue Eng 2006; 12(1): 63-73.

[29] Mason C, Markusen JF, Town MA, Dunnill P, Wang RK. The potential of optical coherence tomography in the engineering of living tissue. Phys Med Biol 2004; 49(7): 1097-115 Review.

[30] Xu X, Wang RK, El Haj A. Investigation of changes in optical attenuation of bone and neuronal cells in organ culture or threedimensional constructs in vitro with optical coherence tomography: relevance to cytochrome oxidase monitoring. Eur Biophys J 2003; 32(4): 355-62.

[31] Han CW, Chu CRN, Adachi A, Usas F, Fu H, Huard J, Pan Y. Analysis of rabbit articular cartilage repair after chondrocytes im- 
plantation using optical coherence tomography. Osteoarthritis Cartilage 2003; 11: 111-121.

[32] Rogowska J, Brezinski ME. Image Processing Techniques for Noise Removal, Enhancement, and Segmentation of Cartilage OCT Images. Phys Med Biol 2002; 47: 641-655.

[33] Czerwinski RN, Jones DL, O'Brien WD. Detection of lines and boundaries in speckle images - Application to medical ultrasound. IEEE Trans Med Imaging 1999; 18: 126-136.
[34] Rogowska J, Brezinski ME. Evaluation of the adaptive speckle suppression filter for coronary optical coherence tomography imaging. IEEE Trans Med Imaging 2000; 12: 1261-6.

[35] Lee YK, Rhodes WT. Nonlinear image processing by a rotating kernel transformation. Opt Lett 1990; 15: 43-46.

[36] Gossage KW, Smith CM, Kanter EM, et al. Texture analysis of speckle in optical coherence tomography images of tissue phantoms. Phys Med Biol 2006; 51(6): 1563-75.

(C) Zheng et al.; Licensee Bentham Open.

This is an open access article licensed under the terms of the Creative Commons Attribution Non-Commercial License (http://creativecommons.org/licenses/ by-nc/3.0/) which permits unrestricted, non-commercial use, distribution and reproduction in any medium, provided the work is properly cited. 